\title{
Health behavior after intrahepatic cholestasis of pregnancy ${ }^{*}$
}

\author{
Kaisa Turunen ${ }^{1 \#}$, Kristiina Helander ${ }^{1}$, Kari J. Mattila ${ }^{1,2}$, Markku Sumanen ${ }^{1}$ \\ ${ }^{1}$ Department of General Practice, School of Medicine, University of Tampere, Tampere, Finland; \\ ${ }^{\#}$ Corresponding Author: kaisa.turunen@uta.fi \\ ${ }^{2}$ Centre for General Practice, Pirkanmaa Hospital District, Tampere, Finland
}

Received 15 November 2012; revised 16 December 2012; accepted 26 December 2012

\section{ABSTRACT}

Background: Pregnancy is an opportunity to adopt favorable health behaviors. We studied whether intrahepatic cholestasis of pregnancy (ICP) promotes favorable health behavior in later life. Design: A prospective controlled cohort study. The method was a questionnaire survey in 2010 among 575 women with ICP and 1374 controls, all having delivered between the years 1969 and 1988 in Tampere University Hospital in Finland. Questionnaires were sent to 544 ICP patients and 1235 controls. Responses were received from 1178 (response rate $66.2 \%$ ). The main outcome measures concerning recent or current health behavior were smoking, alcohol consumption, physical activity, body mass index (BMI) and special diet. Results: Current smoking was less common in the ICP group than among controls $(10.5 \%$ vs $15.7 \%, p=0.017)$. Assessed by smoking pack years there was a similar difference: in the ICP group $11.7 \%$ of women had at least 10 smoking pack years compared to $18.0 \%$ of the controls $(p=0.006)$. Recent alcohol consumption did not separate the two groups. The groups did not differ as to reported physical activity assessed in MET units. Fewer ICP women had had BMIs of $\mathbf{3 0}$ or more during pregnancy compared with controls $(18.8 \%$ vs $25.1 \%, p=0.023)$. In other points of life the BMI differences were not statistically significant. Weight-loss diet and gallbladder diet were more common in the ICP group $(6.3 \%$ vs $3.6 \%, p=0.044$, and $3.0 \%$ vs $1.3 \%, p=0.038)$. Conclusions: Having developed ICP two to four decades earlier seemed to constitute an effective intervention for smoking habits but not for other aspects of health behavior.

*The Centre for General Practice in the Tampere University Hospital District funded the mail survey.
Keywords: Health Behavior; Intrahepatic

Cholestasis of Pregnancy; Smoking; Alcohol Risk

Use; Physical Activity; Body Mass Index

\section{INTRODUCTION}

In female life, pregnancy is an opportunity to adopt health behaviors favorable for later life. Finnish primary care maternity clinics monitor and treat any problems emerging during pregnancy, and also contribute to general health promotion in encouraging pregnant mothers and their families to revise their health behaviors. The free services of the mother health clinics are popular. According to the official birth register $99.8 \%$ of pregnant women attend maternity clinics during their pregnancies [1].

Intrahepatic cholestasis of pregnancy (ICP) usually manifests in the third trimester as skin itching especially on the palms and soles, and as an elevation of serum levels of bile acids and liver enzymes [2,3]. The incidence of ICP in Finland is $0.54 \%-1.5 \%$ of pregnancies [4-6]. The condition recurs in almost half of subsequent pregnancies [2,7]. In one out of six cases it is familial, and in such cases almost always recurs [8].

ICP is thought to be the result of insufficient liver capacity to metabolize high amounts of placental hormones during pregnancy $[2,9]$. In Finland, ICP is usually detected in primary health care maternity clinics, and patients are referred to hospital obstetric clinics for follow-up in view of the risks for the fetus. ICP increases the risk of preterm birth [10-12], fetal distress during labor $[4,10,11,13]$ and intrauterine death $[4,11,13]$.

For the mothers, ICP is a minor problem during pregnancy and delivery except in being associated with an increased incidence of induction and cesarean section [14]. Itching may be intensive and disturbing but rapidly fades postpartum. Moreover, women with a history of ICP are more prone to a number of liver and biliary disorders, including hepatitis $\mathrm{C}$, nonalcoholic liver cirrhosis, gallstones and cholecystitis, and nonalcoholic pancreati- 
tis during their life time, even before the first occurrence of ICP [15].

Our hypothesis was that ICP induced women to lower alcohol consumption, since sufferers are aware of the hepatic origin of the disorder. It is moreover generally known that the liver is responsible for alcohol metabolism. Since cholelithiasis is significantly more common among women with an ICP history, we presumed they would make certain dietary choices, which might also lead to a lowering in weight.

We inquired whether these women had considered their ICP episode to have been so serious that they had adopted favorable health habits for the rest of their lives. We assessed differences in self-reported alcohol use, smoking, physical activity, body mass index (BMI) and in adherence to any special diet between the ICP and control groups.

\section{MATERIAL AND METHODS}

To assess the health history of women who had suffered from ICP, we conducted a mail survey among ICP patients and controls in autumn 2010. Research approval was obtained from the Ethics Committee of the Pirkanmaa Hospital District (R02149).

The study population comprised 575 women who had been diagnosed with ICP at least during one pregnancy (altogether there were 687 cases of ICP) in the obstetric department of Tampere University Hospital in the period 1969-1988. Two controls were selected for each ICP case, i.e. the case previous to and immediately following the ICP case in the maternity ward diary [16]. Mail addresses were obtained from the Population Register Centre in Finland. In the ICP group, 22 women (3.8\%) and in the control group $71(5.2 \%)$ had died by August 2010. Mail addresses were available for 1779 (95\% and 90\%) women. With one reminder, we received 1178 acceptable responses, which corresponds to $66.2 \%$ of all questionnaires sent (Figure 1).

There were no statistically significant differences between the ICP group and the controls regarding age or educational level (Table 1). At the end of the year 2010, the mean age in the ICP group was 58.5 and in the control group 58.3 years. Education was classified as "high" for those who had taken the matriculation examination, and "low" for those who had not.

The main outcome measures concerning women's health behavior were recent alcohol consumption, smoking history, recent physical activity and body mass index (BMI). We also assessed proportions of those maintaining special diets.

Smoking was asked after in several questions: "Have you ever smoked during your life?", "Have you ever smoked regularly (daily or almost daily for at least a

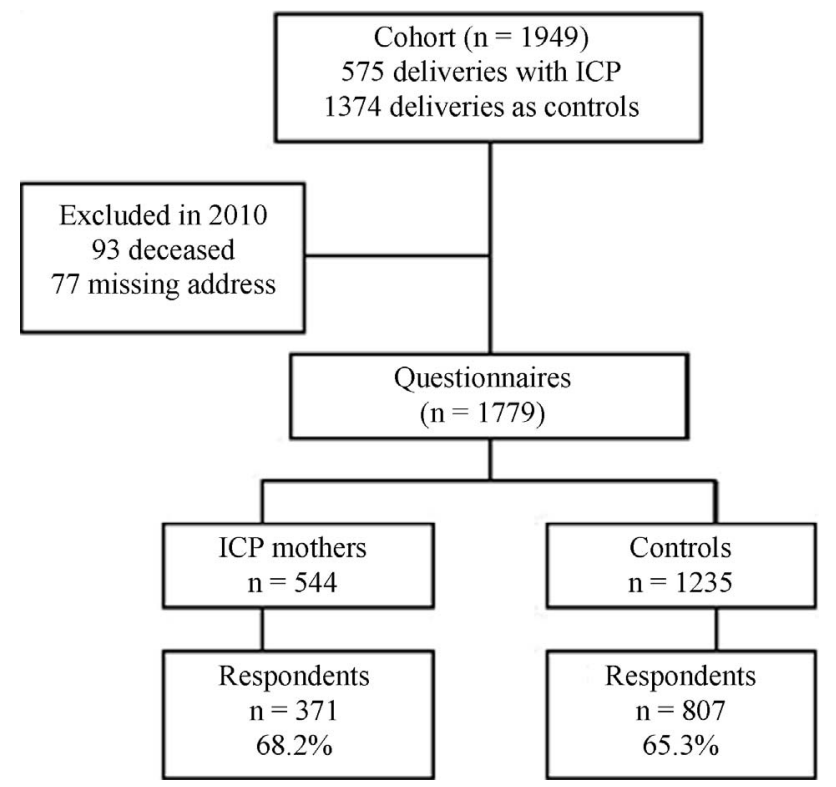

Figure 1. Flow chart of the survey population. ICP, intrahepatic cholestasis of pregnancy.

Table 1. Characteristics of respondents in the ICP and control groups.

\begin{tabular}{ccccc}
\hline & $\begin{array}{c}\text { ICP group } \\
(\mathrm{n}=371)\end{array}$ & $\begin{array}{c}\text { Controls } \\
(\mathrm{n}=807)\end{array}$ & Difference \\
\cline { 2 - 5 } & \multicolumn{1}{c}{$\%$} & \multicolumn{1}{c}{$\%$} & $\%$ units & Significance (p-value) \\
\hline Age (years) & & & & 0.724 \\
$40-49$ & 8.6 & 7.8 & 0.8 & \\
$50-59$ & 45.3 & 48.9 & -3.6 & \\
$60-69$ & 42.0 & 39.0 & 3.0 & \\
$70-89$ & 4.0 & 4.1 & -0.1 & 0.961 \\
Education & & & & \\
Low & 67.0 & 67.2 & -0.2 & \\
High & 33.0 & 32.8 & 0.2 & \\
\hline
\end{tabular}

year)?" and "Do you currently smoke (cigarettes, cigars or pipe tobacco)?" To ascertain smoking pack years, the number of cigarettes per day and the yearly count of smoking were also asked. A smoking pack year corresponds to one pack of 20 cigarettes per day during one year. Alcohol consumption was inquired after by the three-question version of the Alcohol Use Disorders Identification Test (AUDIT-C).

To assess the intensity and average duration of weekly physical exercise the respondents had performed in the past 12 months we used a battery of four questions. Responses were converted into a metabolic equivalent of task units (MET) [17], one MET unit corresponding to the oxygen use of a resting person, which is approximately $3.5 \mathrm{ml} / \mathrm{kg} / \mathrm{min}$. Furthermore, a MET value of two or more was classified as "active" and less than two as "passive".

Women's weights at different points of time in their lives were inquired after as well as their present heights, and BMIs were calculated. In the analysis we used 30 
$\mathrm{kg} / \mathrm{m}^{2}$ as the cut-off point. The questionnaire also included a list of special diets.

Finally, a sum variable of four health behaviors was built. Current non-smoking, alcohol use corresponding to less than 5 points on the AUDIT-C scale, being physically active $(\mathrm{MET} \geq 2)$ and not being obese $(\mathrm{BMI}<30)$ were considered favorable health habits, and all of them were encoded with the value one. All other behaviors were given a value of two. The sum variable score thus varied from four to eight, the value 4 signifying good and 8 bad health habits.

Statistical analyses were made using the SPSS System for Windows; release 20.0. Results were presented as frequencies and percentages. Statistical significance was tested by chi-squared test.

\section{RESULTS}

The ICP group women here included fewer current smokers than the control group $(10.5 \%$ vs $15.7 \%, \mathrm{p}=$ 0.017). A lower proportion of ICP women also had a smoking history involving ten or more smoking pack years $(11.7 \%$ vs $18.0 \%, p=0.006)$ (Table 2$)$. There was no statistically significant difference between the ICP and control groups in respect of alcohol risk use (Table 2). There was, in contrast, a difference in the proportion of women who had not used any alcohol during the last 12 months (18.3\% vs $14.9 \%)$, the difference however not being statistically significant.

Physical activity showed no statistically significant difference between the two groups when all respondents were divided into two groups, "active" and the "passive" group (Table 2). A 6.3\% units lower proportion of BMIs of 30 or more during pregnancy was noted in the ICP group $(18.8 \%$ vs $25.1 \%, \mathrm{p}=0.023)$. The proportion of women with a current or ever BMI value of at least 30 was three per cent units higher in the ICP group, but the difference was not statistically significant (Table 3). Only half of the women reported knowing their own birth weight. Of these, women in the ICP group were somewhat lighter at birth: birth weight proportions less than 2500 grams were $8.0 \%$ vs $5.7 \%$ for ICP and controls respectively, and birth weight proportions of 4500 grams or more were $1.6 \%$ and $5.2 \%$ respectively, the difference not being statistically significant.

The sum variable of the four aspects of health behavior brought out no marked differences between the two groups, only the score eight (=bad health habits) producing a difference of $0.3 \%$ (ICP) vs $1.8 \%$ (controls) ( $\mathrm{p}=$ 0.037 ) in favor of the ICP women.

Among the ICP women $3.0 \%$ and in the control group $1.3 \%(\mathrm{p}=0.038)$ reported maintaining a gallbladder diet, and $6.3 \%$ vs $3.6 \%(\mathrm{p}=0.044)$ followed a weight-loss diet (Table 4). None in the ICP group and only $1.4 \%$ in the control group reported adherence to a vegetarian diet $(\mathrm{p}=0.024)$.

\section{DISCUSSION}

Current smoking was less common in the ICP than the control group, and this also pertained to smoking pack years. Recent use of alcohol showed no marked differences. As to physical activity and obesity the groups did not differ significantly.

Table 2. Alcohol use ${ }^{*}$, smoking and physical activity in the ICP and control groups.

\begin{tabular}{|c|c|c|c|c|}
\hline & \multirow{2}{*}{$\begin{array}{c}\text { ICP group } \\
(\mathrm{n}=371) \\
\%\end{array}$} & \multirow{2}{*}{$\begin{array}{c}\text { Controls } \\
(\mathrm{n}=807) \\
\%\end{array}$} & \multicolumn{2}{|c|}{ Difference } \\
\hline & & & $\%$ units & $\begin{array}{c}\text { Significance } \\
\text { (p-value) }\end{array}$ \\
\hline Alcohol use/Audit $C^{*}$ score & & & & 0.652 \\
\hline $0-4$ & 81.0 & 82.1 & -1.1 & \\
\hline$\geq 5$ & 19.0 & 17.9 & 1.1 & \\
\hline Current smoking & & & & 0.017 \\
\hline Smoking & 10.5 & 15.7 & -5.2 & \\
\hline Non-smoking & 89.5 & 84.3 & 5.2 & \\
\hline Smoking pack years & & & & 0.006 \\
\hline$<10$ years & 88.3 & 82.0 & 6.3 & \\
\hline$\geq 10$ years & 11.7 & 18.0 & -6.3 & \\
\hline Physical activity & & & & 0.765 \\
\hline Passive (MET/day < 2) & 29.5 & 30.4 & -0.9 & \\
\hline Active (MET/day $\geq 2)$ & 70.5 & 69.6 & 0.9 & \\
\hline
\end{tabular}

*Audit-C: the cut-off point for high risk alcohol use for women is 5 or more. 
Table 3. Proportions of body mass index $\left(\mathrm{BMI} \mathrm{kg} / \mathrm{m}^{2}\right)$ at different points of life in the ICP and control groups.

\begin{tabular}{|c|c|c|c|c|}
\hline & \multirow{2}{*}{$\begin{array}{c}\text { ICP group } \\
(\mathrm{n}=336-365)^{*} \\
\%\end{array}$} & \multirow{2}{*}{$\begin{array}{c}\text { Controls } \\
(\mathrm{n}=722-792)^{*} \\
\%\end{array}$} & \multicolumn{2}{|c|}{ Difference } \\
\hline & & & $\%$ units & $\begin{array}{c}\text { Significance } \\
\text { (p-value) }\end{array}$ \\
\hline BMI in 2010 & & & & 0.257 \\
\hline $\mathrm{BMI}<30$ & 73.7 & 76.8 & -3.1 & \\
\hline $\mathrm{BMI} \geq 30$ & 26.3 & 23.2 & 3.1 & \\
\hline BMI at 20 years & & & & 0.071 \\
\hline $\mathrm{BMI}<30$ & 100.0 & 99.1 & 0.9 & \\
\hline $\mathrm{BMI} \geq 30$ & 0.0 & 0.9 & -0.9 & \\
\hline Highest BMI during pregnancy & & & & 0.023 \\
\hline $\mathrm{BMI}<30$ & 81.2 & 74.9 & 6.3 & \\
\hline $\mathrm{BMI} \geq 30$ & 18.8 & 25.1 & -6.3 & \\
\hline Highest BMI ever & & & & 0.279 \\
\hline $\mathrm{BMI}<30$ & 65.2 & 68.5 & -3.3 & \\
\hline $\mathrm{BMI} \geq 30$ & 34.8 & 31.5 & 3.3 & \\
\hline
\end{tabular}

${ }^{*}$ The number of respondents varies because respondents chose not to answer all questions.

Table 4. Special diets (\%) among women in the ICP and control groups.

\begin{tabular}{|c|c|c|c|c|}
\hline \multirow[b]{2}{*}{ Special diet } & \multirow{2}{*}{$\begin{array}{c}\text { ICP group } \\
(\mathrm{n}=366) \\
\%\end{array}$} & \multirow{2}{*}{$\begin{array}{c}\text { Controls } \\
(\mathrm{n}=795) \\
\%\end{array}$} & \multicolumn{2}{|c|}{ Difference } \\
\hline & & & $\%$ units & $\begin{array}{l}\text { Significance } \\
\text { (p-value) }\end{array}$ \\
\hline Lactose-free or low-lactose diet & 16.7 & 17.2 & -0.5 & 0.812 \\
\hline Gluten-free diet & 2.5 & 2.9 & -0.4 & 0.675 \\
\hline Gallbladder diet & 3.0 & 1.3 & 1.7 & 0.038 \\
\hline Low-fat or low-cholesterol diet & 14.8 & 13.6 & 1.2 & 0.593 \\
\hline Weight-loss diet & 6.3 & 3.6 & 2.7 & 0.044 \\
\hline Vegetarian diet & 0.0 & 1.4 & -1.4 & 0.024 \\
\hline Other special diet & 7.9 & 6.0 & 1.9 & 0.230 \\
\hline
\end{tabular}

The study population, which comprised diagnosed ICP cases and controls who had all delivered in Tampere University Hospital in 1969-1988, was comprehensive. The two groups did not differ significantly in respect of age or educational level. The answers concerning maintenance of a lactose-free or low-lactose diet (17\%) corresponded to the known prevalence of lactose intolerance in the Finnish adult population [18], which also confirms the comparability of the groups.

In international terms, the response rate $(66.2 \%)$ can be regarded as high for a mail survey [19]. One explanation for this might be that we designed the questionnaire to be as practical as possible so that respondents could fill it in at one sitting. An e-mail survey might have resulted in a higher response rate among younger women. As a whole, the mail survey provided us with abundant information on individual health habits which would not have been revealed by searches in national disease registers.

A Finnish study from 2004 showed that working-aged coronary heart disease patients persisted in smoking and being obese more often than controls, which would imply that secondary prevention in this disease is disappointing [20]. Based on our responses, an ICP episode during a pregnancy seems to act for certain individuals as some kind of intervention, as the number of smokers was lower among the ICP women compared to the controls. One explanation for this might be that smokers in the ICP group may have quit smoking because of dyspepsia which is more common among smokers than non-smokers. Quitting smoking alleviates gastroesophageal reflux symptoms [21]. Our recent study among the same population showed that women in the ICP group had used antacid drugs more often than the controls [16]. 
We considered it likely that alcohol use would be markedly lower among former ICP sufferers compared to controls, but this was not the case. It is possible that ICP women consider the disorder to be connected solely with pregnancy and hence see no need to maintain alcohol restrictions later in life. As hepatobiliary diseases were more common among ICP women than controls [16], a moderate restrictive recommendation for alcohol use might be useful after an ICP episode.

The lower proportion of ICP women with a BMI of 30 or more during pregnancy might be explained by their having had earlier deliveries than the controls [14].

In our recent study, breast cancer and hypothyreosis were more common in the ICP than the control group [16]. These diseases cannot ultimately be avoided by favorable health habits. Of cardiovascular disorders, high blood pressure on medication, high cholesterol on medication and cardiac arrhythmia were less common in the ICP than in the control group. These are all conditions which can be influenced by favorable health habits.

According to our findings, there were few long-term associations between ICP and subsequent health behaviors. ICP had no marked effect on respondents' alcohol consumption, although in view of the hepatobiliary origins of the condition a connection with reduced alcohol use might have been expected. On the other hand, our findings showed that ICP was associated with lower smoking frequency compared to controls. This is a new result which warrants further research.

\section{REFERENCES}

[1] National Institute for Health and Welfare (2012) Finland. http://www.thl.fi/fi_FI/web/kasvunkumppanit-fi/palvelut/ neuvolat/aitiysneuvola

[2] Reyes H. (1997) Review: Intrahepatic cholestasis. A puzzling disorder of pregnancy. Journal of Gastroenterology and Hepatology, 12, 211-216. doi:10.1111/j.1440-1746.1997.tb00410.x

[3] Lammert, F., Marschall, H.U., Glantz, A. and Matern, S. (2000) Intrahepatic cholestasis of pregnancy: Molecular pathogenesis, diagnosis and management. Journal of Hepatology, 33, 1012-1021. doi:10.1016/S0168-8278(00)80139-7

[4] Laatikainen, T. and Tulenheimo, A. (1984) Maternal serum bile acid levels and fetal distress in cholestasis of pregnancy. International Journal of Gynecology \& Obstetrics, 22, 91-94. doi:10.1016/0020-7292(84)90019-5

[5] Berg, B., Helm, G., Petersohn, L. and Tryding, N. (1986) Cholestasis of pregnancy. Clinical and laboratory studies. Acta Obstetricia et Gynecologica Scandinavica, 65, 107113. doi:10.3109/00016348609158363

[6] Heinonen, S. and Kirkinen, P. (1999) Pregnancy outcome with intrahepatic cholestasis. Obstetrics \& Gynecology, 94, 189-193.doi:10.1016/S0029-7844(99)00254-9
[7] Germain, A.M., Carvajal, J.A., Glasinovic, J.C., Kato, C.S. and Williamson, C. (2002) Intrahepatic cholestasis of pregnancy: An intriguing pregnancy-specific disorder. Journal of the Society for Gynecologic Investigation, 9, 10-14. http://rsx.sagepub.com/content/9/1/10.full.pdf

[8] Savander, M., Ropponen, A., Avela, K., Weerasekera, N., Cormand, B., Hirvioja, M.L., et al. (2003) Genetic evidence of heterogeneity in intrahepatic cholestasis of pregnancy. Gut, 52, 1025-1029. doi:10.1136/gut.52.7.1025

[9] Davidson, K.M. (1998) Intrahepatic cholestasis of pregnancy. Seminars in Perinatology, 22, 104-111. doi:10.1016/S0146-0005(98)80042-6

[10] Glantz, A., Marschall, H.U. and Mattsson, L.A. (2004) Intrahepatic cholestasis of pregnancy: Relationships between bile acid levels and fetal complication rates. Hepatology, 40, 467-474. doi:10.1002/hep.20336

[11] Fisk, N.M. and Storey, G.N. (1988) Fetal outcome in obstetric cholestasis. British Journal of Obstetrics and Gynaecology, 95, 1137-1143. doi:10.1111/j.1471-0528.1988.tb06791.x

[12] Rioseco, A.J., Ivankovic, M.B., Manzur, A., Hamed, F., Kato, S.R., Parer, J.T., et al. (1994) Intrahepatic cholestasis of pregnancy: A retrospective case-control study of perinatal outcome. American Journal of Obstetrics \& Gynecology, 170, 890-895.

[13] Alsulyman, O.M., Ouzounian, J.G., Ames-Castro, M. and Goodwin, T.M. (1996) Intrahepatic cholestasis of pregnancy: Perinatal outcome associated with expectant management. American Journal of Obstetrics \& Gynecology, 175, 957-960. doi:10.1016/S0002-9378(96)80031-7

[14] Turunen, K., Sumanen, M., Haukilahti, R.L., Kirkinen, P. and Mattila, K. (2010) Good pregnancy outcome despite intrahepatic cholestasis. Scandinavian Journal of Primary Health Care, 28, 102-107. doi:10.3109/02813431003784001

[15] Ropponen, A., Sund, R., Riikonen, S., Ylikorkala, O. and Aittomaki, K. (2006) Intrahepatic cholestasis of pregnancy as an indicator of liver and biliary diseases: A population-based study. Hepatology, 43, 723-728. doi:10.1002/hep.21111

[16] Turunen, K., Mölsä, A., Helander, K., Sumanen, M. and Mattila, K.J. (2012) Health history after intrahepatic cholestasis of pregnancy. Acta Obstetricia et Gynecologica Scandinavica, 9, 679-685. doi:10.1111/j.1600-0412.2012.01403.x

[17] Wilson, W.F., Paffenbarger, R.S., Morris, J.N. and Havlik, R.J. (1986) Assessment methods for physical activity and physical fitness in population studies: Report of NHLBI workshop. American Heart Journal, 111, 1177-1192. doi:10.1016/0002-8703(86)90022-0

[18] Rasinperä, H. (2006) Adult-type hypolactasia: Genotypephenotype correlation. Thesis, University of Helsinki. http://www.doria.fi/bitstream/handle/10024/1389/adulttyp .pdf? sequence $=1$

[19] Asch, D.A., Jedrziewski, M.K. and Christakis, N.A. (1997) Response rates to mail surveys published in medical journals. Journal of Clinical Epidemiology, 50, 1129 1136. doi:10.1016/S0895-4356(97)00126-1 
[20] Sumanen, M., Koskenvuo, M., Immonen-Räihä, P., Suominen, S., Sundell, J. and Mattila, K. (2004) Secondary prevention of coronary heart disease is disappointing among patients of working age. Family Practice, 21, 304-306. doi:10.1093/fampra/cmh315
[21] Nakajima, K., Nagahara, A., Kurosawa, A., Seyama, K., Asaoka, D., Osada, T., Hojo, M. and Watanabe, S. (2011) Quit smoking improves gastroesophageal reflux symptoms and quality of life. Health, 3, 677-683. doi:10.4236/health.2011.311114 